\title{
Power Sharing and Control by Droop Controller with Advanced Filter Design: A Case Study in Lock-down Periods
}

\author{
Bharat Modi ${ }^{*}$, Mahendra Lalwani \\ Department of Electrical Engineering, Rajasthan Technical University Kota, Rajasthan, India \\ Received 20 July 2020; received in revised form 13 March 2021; accepted 14 March 2021 \\ DOI: https://doi.org/10.46604/peti.2021.6106
}

\begin{abstract}
In the lock-down period, the islanding mode of operation with droop controllers has several advantages in the alternating current grid. This study focuses on an improvised droop controller. It consists of an advanced filtering segment embedded with a conventional droop controller, which overcomes the drawback of droop controllers of the non-handling of non-linear loads in an ordinary situation. A selective harmonic elimination technique in grid-connected mode and lock-down mode and an advanced filter embedded with droop control are used so that the proposed controller can also work as an Active Harmonic Filter (AHF). The simulation results in different cases show that the proposed controller can control the active and reactive power in the lock-down period as well as the harmonics in the normal period up to an extent.
\end{abstract}

Keywords: islanding, droop controller, active harmonic filter (AHF), selective harmonic generation (SHG)

\section{Introduction}

Several blackouts of grids were faced in the early 1990s, but the lock-down situation is unique in several ways. There are significant differences, e.g., the lock-down period is longer than the blackout period. Therefore, the need for electrical power is being decreased for a long duration. However, the disturbance is a severe condition (90 percent of the industry load has been shut down), not only from a stability aspect but also from an economic point of view. The best way to deal with this problem is to disconnect the conventional grid and convert it into the Micro-grid (MG) supplied with Distributed Generation (DG) [1]. MG is a group of generation sources, loads, etc. DG is one of the attractive solutions with many advantages [2].

The operation of DG can be broadly classified into two categories: current-controlled (grid following) and voltage-controlled (grid forming). The latter is also known as the islanding mode of power sharing and control, which is most widely used in the droop controller in islanded mode. There are two principal tasks to perform the droop controller proportionately and maintain the voltage and frequency stability. Thus, the MG connected with DG requires a high energy management technique, as described in [3]. The novel control scheme of decoupled trigonometric saturated controller is discussed to improve the power-sharing accuracy with better stability. Moreover, this method provides robust decoupling with guarantees for both voltage and frequency stability [4]. Power sharing and control are mostly based on the droop concept. However, the conventional droop controller focuses on fundamental components of power and ignores the harmonics of the non-linear load [5]. Several control strategies, such as master-slave control and average current-sharing control, have been widely implemented worldwide to operate parallel-connected inverters for load sharing in the DG network. Among these techniques, due to the lack of essential communication links between parallel-connected inverters, the droop control technique has been widely accepted in the scientific community [6]. However, no strategy is applied in a lock-down situation.

* Corresponding author. E-mail address: bharatalone@gmail.com 
The main objective of this study is to design an advanced filtering segment embedded with a conventional droop controller, which overcomes the drawback of droop controllers of the non-handling of non-linear loads in a lock-down situation. In a normal period, the droop controller pulse generator works on the principle of Selective Harmonic Generation (SHG) so that the droop controller supplies harmonics and works as an Active Harmonic Filter (AHF).

\section{Power-Sharing Control}

The MG power-sharing control in inverter-controlled mode is broadly classified into two categories.

\subsection{Communication based control}

This control strategy requires communication lines between modules and controllers, resulting in the increased cost of the whole system. Long-distance communication lines can be easier to get interfered with noise. Thus, the expandability and reliability of the system is reduced.

\subsection{Wireless based or droop control}

Droop control is sometimes also known as a wireless controller [5]. This method does not require any wired connection. Despite this, several other advantages are associated with this method, e.g. less complexity, less cost, improved redundancy, improved reliability, and more natural.

If islanding is unintentional, then islanding should be detected. It can be detected by passive or active methods (measurements). In the passive method, the autocorrelation function of modal current is used [5]. Another detection scheme based on the rate of change of exciter voltage is used for detecting unintentional islanding [6]. The other detection methods are vector jump detection and voltage harmonics detection [7-9].

Droop controlled methods are applied to achieve power sharing of fundamental components. However, in non-linear loads, droop control does not consider the harmonic associated with it [10]. As a consequence, high circulating current and poor power quality are generated. To solve this problem, two approaches are given in this paper. The fundamental equations used for the droop control problem are as follows:

$$
\begin{aligned}
P_{i} & =\frac{V E_{i}}{X} \sin \varphi \\
Q_{i} & =\frac{V E_{i} \cos \cos \varphi-V^{2}}{X}
\end{aligned}
$$

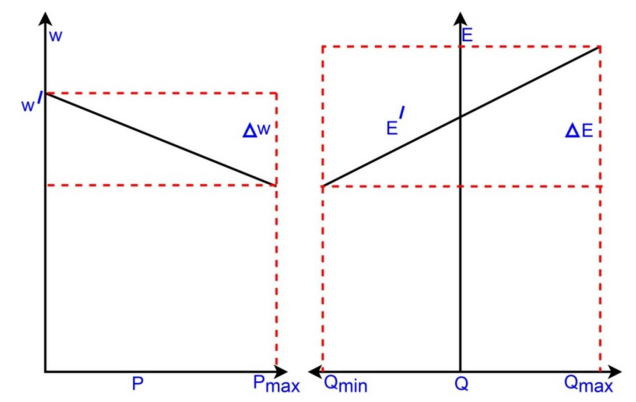

Fig. 1 Basic characteristics of droop controller

where $X$ is the reactance of inverter, $\varphi$ is the angle between the output voltage of inverter and common bus, $E_{i}$ is the output voltage of inverter, and $V$ is grid voltage. It is noted that the active power depends on the angle, and the reactive power depends on the voltage magnitude. This principle can be applied in Voltage Source Inverter (VSI) by using the P/Q droop controller (as shown in Fig. 1) [10-11]. 


$$
\begin{aligned}
& f_{\text {rated }}=f_{i}-m\left(P_{i}-P_{\max }\right) \\
& E_{\text {rated }}=E_{i}-n\left(Q_{i}-Q_{\max }\right)
\end{aligned}
$$

Here, $m$ and $n$ are droop slopes; $i$ is the index of the inverter; $f_{\text {rated }}, E_{\text {rated }}, P_{\text {max }}$, and $Q_{\text {max }}$ are the nominal frequency, voltage, active power, reactive power rating respectively. The value of $m$ and $n$ are chosen to affect the stability of the system. In a similar concept, further researchers found a relationship between angle and power, i.e., the phase angle is set to common timing. Power requirements can be shared based on an angle of the conventional droop controller. The angle droop controller is described as follows [12].

$$
\delta_{i}=\delta_{\text {rated }}-m\left(P_{i}-P_{i, \text { rated }}\right)
$$

\section{Filter Designing}

By the use of power converters, we can maximize the power transfer from renewable energy sources. Therefore, power converters are essential, but every power converter associates with harmonics, and there is an essential requirement of filters. The first key step is to connect a simple inductor in series, but the harmonic attenuation provided by the series filter is not prominent as the ripple injected does not meet the standard. In addition to it, the voltage drop is very high and the inductor required is very heavy. Thus, in compariosn with L filter, LCL filter is much more pronounced [13-14].

Here the LC filter is considered because it involves a second inductor due to the stray effect (as shown in Fig. 2). Furthermore, it is considered due to the uncertainties and disturbances found in such applications with various LCL filter parameters [15]. The capacitor $\left(\mathrm{C}_{\mathrm{f}}\right)$ cannot be placed at the inverter side because it will be converted into the current source, and then the whole current will go through a grid. In a practical grid, there will be some stray impedance of transformer, lines, etc. For this reason, the LCL filter is proposed. A second inductor is also connected with the stray inductor.

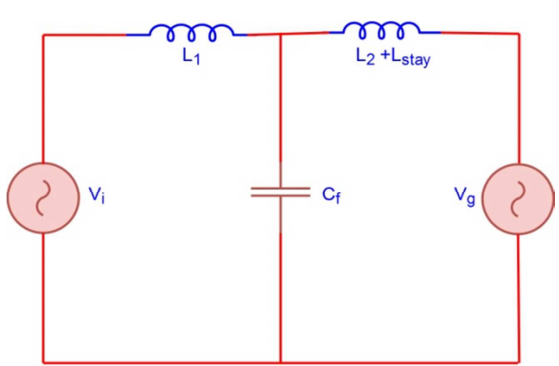

Fig. 2 The introduction of stray capacitance

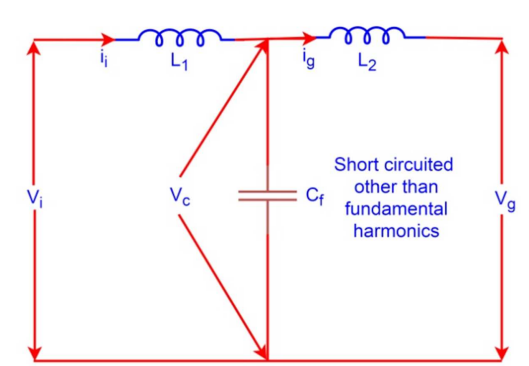

Fig. 3 The LCL filter per phase model

\subsection{The LCL filter modeling}

In Fig. 3, a per phase model of the LCL filter is shown. Here, t-type filter is considered. This is especially designed to reduce harmonics of voltage or current absorbed by nonlinear load or grid, with a droop controller output stage. The transfer function of this circuit is defined as the ratio of output to input quantity. In this case, the output quantity is current $\left(i_{g}\right)$, and the input quantity is voltage $\left(V_{i}\right)$.

$$
\frac{i_{g}(s)}{V_{i}(s)}=\frac{1}{s L_{1}+\frac{\frac{s L_{2}}{s C}}{s L_{2}+\frac{1}{s C}}} \times \frac{\frac{1}{s C}}{\frac{1}{s C}+s L_{2}}
$$




$$
\begin{aligned}
& L=L_{1}+L_{2} \\
& L_{p}=\frac{L_{1} L_{2}}{L_{1}+L_{2}} \\
& w_{r}=\frac{1}{\sqrt{L_{p} C}} \\
& \frac{i_{g}(s)}{V_{i}(s)}=\frac{\frac{1}{L}}{s\left[1+\left(\frac{s}{w_{r}}\right)^{2}\right]}
\end{aligned}
$$

\subsection{The choice of $L_{1}$ and $L_{2}$}

The choice of $\mathrm{L}_{1}$ and $\mathrm{L}_{2}$ is expressed as Eq. (11) and Eq. (12).

$$
\begin{aligned}
& L_{1}=a L_{2} \\
& L=\frac{(1+a)^{2}}{w_{r}^{2} a C}
\end{aligned}
$$

$L_{\text {min }}$ is required when a=1, keeping $w_{r}$ and $C$ constant [9]. The ripple in the minimum value of $i_{g}$ is for fixed $L$ and $C$ when $\mathrm{a}=1$. For fixed $i_{g}$ ripple and fix $L$ requirement, the $C$ requirement is minimum when $\mathrm{a}=1$. If the grid voltage and current are in the same phase (as shown in Fig. 4(a)), then the requirement of the inductor is less and close to $L_{\text {min }}$. The value of lagging power factor (as shown in Fig. 4(b)) is between $L_{\min }$ and $L_{\max }$ according to Eq. (13).

$$
L_{\min } \leq L \leq L_{\max }
$$

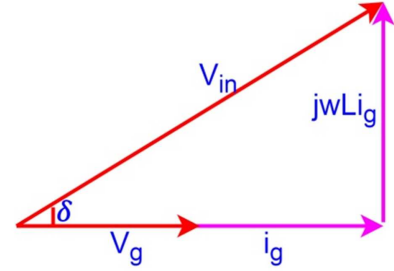

(a) At unity power factor

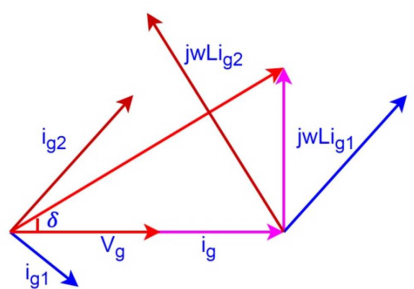

(b) Lagging power factor

Fig. 4 Phasor diagrams

\subsection{The choice of capacitor $C$}

A choice of capacitance depends on optimizing total reactive power loss. The above described characteristics should be kept in mind while designing the LCL filter. A limit on the reactive power requirement of the filter gives the maximum value of capacitance $\left(C_{\max }\right)$.

$$
\begin{aligned}
& Q_{\text {cap }}=V^{2} w_{0} C \\
& C_{\text {max }}=\frac{Q_{\max }}{V^{2} w_{0}}
\end{aligned}
$$


The reactive power requirements may cause capacitor resonance when a capacitor is interacting with the grid. Passive or active damping can be adopted to resolve the problem by using an algorithm to design an LCL filter [14]. The parameters required for designing the LCL filter include $V_{L}$ (line to line root mean square voltage in inverter output), $V_{p}$ (phase voltage-inverter output), $P$ (rated active power in Watt), $V_{d c}$ (direct current link voltage), $f_{g}$ (grid frequency), $f_{s w}$ (switching frequency), and $f_{\text {res }}$ (resonance frequency), as shown in Table 1. The base values of impedance and capacitance are as follows:

$$
\begin{aligned}
& Z_{b}=\frac{k \times V_{L}^{2}}{P} \\
& C_{b}=\frac{1}{w_{g} Z_{b}}
\end{aligned}
$$

The variation of maximum power factor $k$ is 0.15 (15\%), the maximum ripple tolerance $r$ is $0.10(10 \%)$, and the attenuation factor $x$ is $0.20(20 \%) . V_{d c}$ is calculated by considering nominal alternating current voltage variation ( $+5 \%$ factor), filter voltage drop $(+10 \%$ factor), and the dead band in the pulse width modulation output (5\% factor):

$$
\begin{aligned}
& V_{m} \times 1.05 \times 1.05 \times 1.1=\frac{V_{d c}}{2} \\
& I_{\max }=\frac{P \sqrt{2}}{3 V_{P}} \\
& I_{L_{\text {max }}}=r I_{\text {max }}=0.1 I_{\text {max }} \\
& L_{1}=\frac{V_{d c}}{6 f_{s w} I_{L m a x}} \\
& L_{2}=\frac{\sqrt{\frac{1}{x^{2}}}+1}{C_{f} w_{s w}^{2}} \\
& C_{f}=k C_{b}
\end{aligned}
$$

To avoid the situation of resonance, a small series resistance is required to be connected with the filter capacitor to attenuate some parts of the ripples. The resonant frequency should lie in range (Eq. (25)). If it is not, then the attenuation factor is to be changed. The maximum and minimum limit of resonant frequency are described as follows:

$$
\begin{gathered}
w_{r e s}=\sqrt{\frac{L_{1}+L_{2}}{L_{1} L_{2} C_{f}}} \\
10 f_{g}<f_{r e s}<0.5 f_{s w}
\end{gathered}
$$

The value of the series resistor should be typically one-third of the impedance of the filter capacitor at the resonant frequency and can be calculated by Eq. (26).

$$
R_{f}=\frac{1}{3 w_{r e s} C_{f}}
$$


Table 1 The parameters of LCL filter

\begin{tabular}{|c|c|c|}
\hline Symbol & Name & Values \\
\hline$f_{g}$ & Grid frequency & $50 \mathrm{~Hz}$ \\
\hline$f_{s w}$ & Switching frequency & $10 \mathrm{kHz}$ \\
\hline$P$ & Nominal Power & $5 \mathrm{~kW}$ \\
\hline$V_{L}$ & Inverter output line voltage & $440 \sqrt{3} \mathrm{~V}$ \\
\hline$V_{d c}$ & Direct current link voltage & $1509.27 \mathrm{~V}$ \\
\hline$L_{1}$ & Inverter side inductor & $1.174 \mathrm{mH}$ \\
\hline
\end{tabular}

\subsection{The design of direct current link capacitor}

As per IEEE 1547 standard, the value of current can be utilized for capacitor designing [16], as shown in Eq. (30). According to the standard, the ripple current should not be more than $5 \%$.

$$
\begin{aligned}
& I_{a c}(a t 50 \mathrm{~Hz})=\frac{I_{a c}}{2} \\
& i_{\text {out }}\left(n T_{s w}\right)=I_{a c} \cos \cos 2 \pi 50 n T \\
& d(n) \cong 0.5+\frac{230 \sqrt{2}}{800} \cos \cos 2 \pi 50 n T_{s w} \\
& I_{a c_{\_} a t_{\_} s w f}=\left\{\frac{1}{N} \sum_{i=1}^{N} i_{o u t}^{2}\left(n T_{s w}\right)\left[d(n)-d(n)^{2}\right]\right\}^{1 / 2} \\
& I_{r m s}=\left(I_{a c_{a t_{50} \mathrm{~Hz}}}^{2}+I_{d c}^{2}+I_{a c_{a t_{\text {fsw }}}}^{2}\right)^{1 / 2}
\end{aligned}
$$

\section{Selective Harmonic Generation (SHG)}

SHG is a technique emerged from selective harmonic elimination. In this technique, a designed pulse generator with the appropriate value of $\alpha_{1}, \alpha_{2}$, and so on, can be implemented easily. Therefore, before the generation of pulse, a non-linear load is to be modeled as:

$$
V=E_{0} \sin w t+\frac{E_{0}}{5} \sin 5 w t+\frac{E_{0}}{7} \sin 7 w t+\ldots
$$

The fundamental component can be described as:

$$
V_{1}=1-2 \cos \alpha_{1}+2 \cos \alpha_{2}=0.8
$$

The $5^{\text {th }}$ harmonic component is:

$$
V_{5}=1-2 \cos 5 \alpha_{1}+2 \cos 5 \alpha_{2}=0.2
$$

The $7^{\text {th }}$ harmonic component is:

$$
V_{7}=1-2 \cos 7 \alpha_{1}+2 \cos 7 \alpha_{2}=0.142857
$$



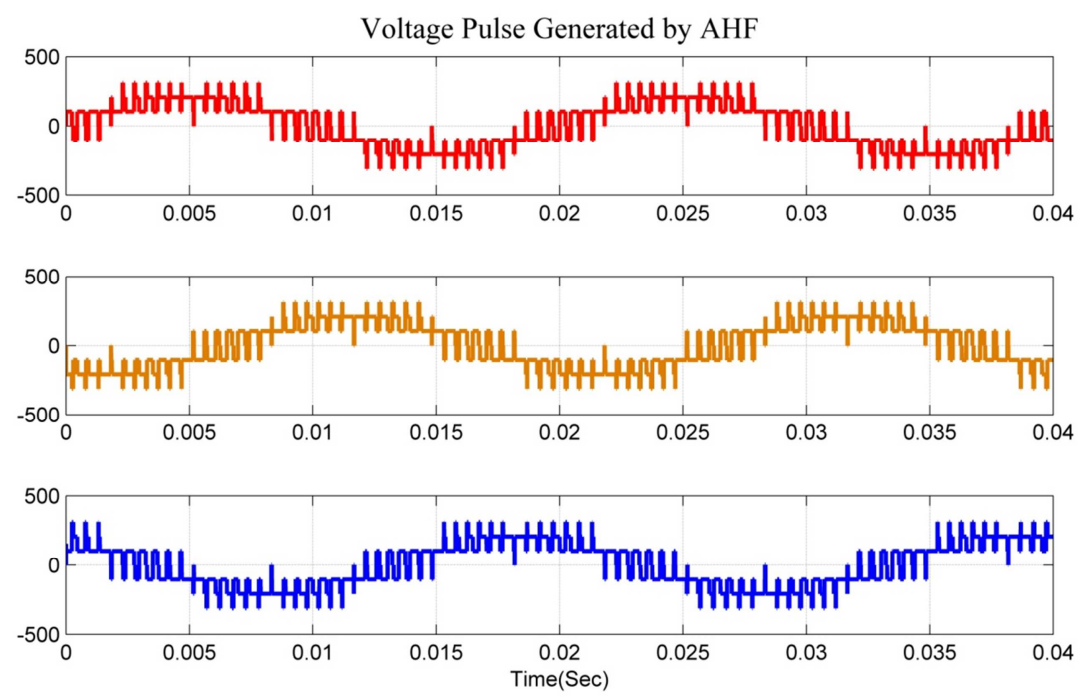

Fig. 5 The pulse generation for suppling the $5^{\text {th }}$ harmonic

The $3^{\text {rd }}$ harmonic and the multiples of $3^{\text {rd }}$ harmonic eliminate in line to line voltage. By solving Eqs. (33) and (34), the value of $\alpha_{1}$ and $\alpha_{2}$ will be: $\alpha_{1}=25.3592^{\circ}, \alpha_{2}=36.5208^{\circ}$. The pulse generated by the pulse generator to supply a $5^{\text {th }}$ harmonic component is shown in Fig. 5. By solving Eqs. (33) and (35), the value of $\alpha_{1}$ and $\alpha_{2}$ will be: $\alpha_{1}=16.1859^{\circ}, \alpha_{2}=30.6427^{\circ}$. Sometimes instead of two switching values in quarter-wave symmetry, three switching instances can be used by which Total Harmonic Distortion (THD) is further reduced. The fundamental component can be described as:

$$
V_{1}=1-2 \cos \alpha_{1}+2 \cos \alpha_{2}-2 \cos \alpha_{3}=0.8
$$

The $5^{\text {th }}$ harmonic component is:

$$
V_{5}=1-2 \cos 5 \alpha_{1}+2 \cos 5 \alpha_{2}-2 \cos 5 \alpha_{3}
$$

The $7^{\text {th }}$ harmonic component is:

$$
V_{7}=1-2 \cos 7 \alpha_{1}+2 \cos 7 \alpha_{2}-2 \cos 7 \alpha_{3}
$$

By solving Eqs. (36), (37), and (38), the value of $\alpha_{1}, \alpha_{2}$, and $\alpha_{3}$ will be: $\alpha_{1}=23.5774^{\circ}, \alpha_{2}=21.9858^{\circ}, \alpha_{3}=83.6411^{\circ}$.

\section{The Proposed Technique}

When the grid and the inverter-connected renewable sources feed, then the load operates broadly in the following two conditions [17]: a) On-grid and b) Off-grid islanding mode (as shown in Fig. 6). If the load is connected to the grid, in this case, the grid controls the voltage and frequency. The droop controller works as an active power filter by using SHG technique. Hence, the possibility of low harmonics ripple is reduced. In the second case, an islanding mode inverter works as VSI. We design a passive filter for improving the waveform of inverter output, then the power is sharing according to the droop control concept. The roles of droop controller are as follows.

\subsection{On grid with nonlinear load}

In this case, harmonics are generated by the inverter [18] with reverse polarity and the same amplitude of non-linear load harmonics. The droop controller pulse generator works on the principle of SHG (as shown in Fig. 7). The droop controller supplies harmonics. Thus, THD is reduced. Therefore, the droop controller functions as AHF. The simulation studies are carried out using MATLAB. The active filters are tuned non-linear load at the $5^{\text {th }}$ harmonic, the $7^{\text {th }}$ harmonic, and the 
combination of the $5^{\text {th }}$ and $7^{\text {th }}$ harmonics of the fundamental frequency, and the control signals of Insulated Gate Bipolar Transistors (IGBTs) are generated through the pulse generator with the calculation of switching angle (in section 5) using MATLAB coding.

\subsection{Off grid by droop controller}

In this case, the filter is designed precisely (as discussed in section 3). Overall, THD gets reduced. This is the reason why this type of droop controller is known as an improvised droop controller. The block diagram is shown in Fig. 6.

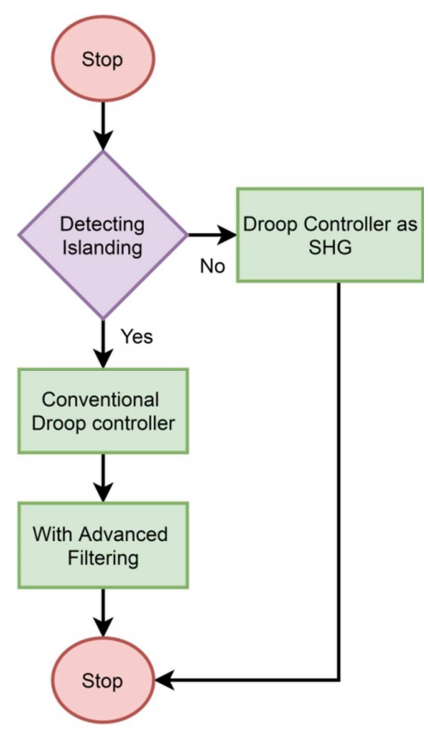

Fig. 6 The working process of droop controller

The working process of the droop controller is explained by using block diagram in Fig. 6. In the islanding mode, it works as a conventional droop controller with an advanced filtering facility. In the grid-connected mode (if islanding does not occur), it works as AHF for power quality improvement. In this situation, the harmonics required by the non-linear load are supplied by changing the switching instant of the inverter pulse generator, and are embedded with a droop controller.

\subsection{Simulation model}

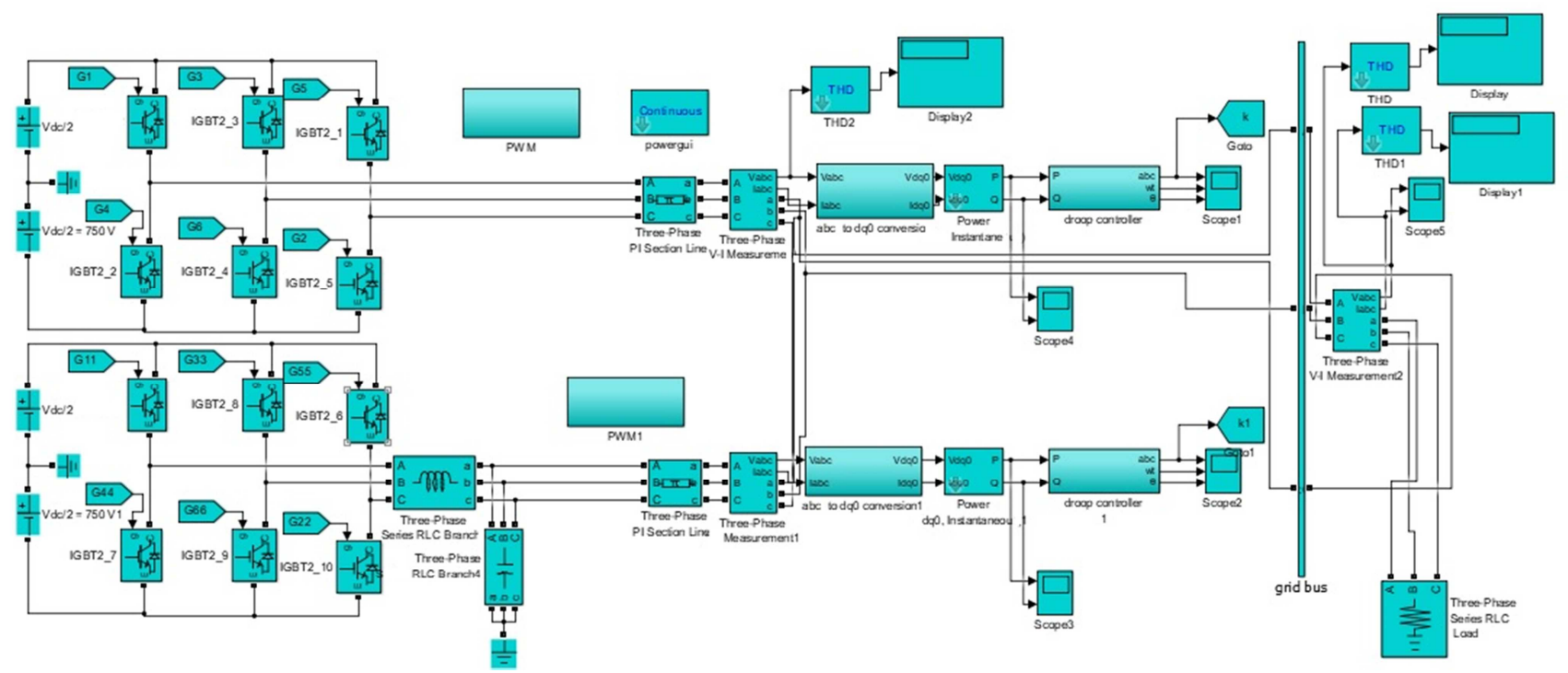

Fig. 7 The Simulink model of the off-grid conventional droop controller

A simulation model of the droop controller is represented in Fig. 7 in which two different DG systems are connected to examine their respective power-sharing. The simulation setting of POWERGUI is shown in Table 2. 
Table 2 The simulation setting of POWERGUI

\begin{tabular}{|c|c|}
\hline Solver & ODE23tb(Stiff/TR/BDF2) \\
\hline Carrier frequency & $10,000 \mathrm{~Hz}$ \\
\hline Simulation Time & $0.08 \mathrm{Sec}(4 \mathrm{Cycles})$ \\
\hline Discrete step time & $2 \times 10^{-6} \mathrm{Sec}$ \\
\hline
\end{tabular}

\section{Results}

\subsection{Case 1: when a non-linear load is supplied by the grid without AHF}

The system is simulated for a purely resistive load of $13.6 \mathrm{kV}$ and $50 \mathrm{kVA}$ as a base value. If AHF is not connected, the non-linear load is composed of the fundamental, the $5^{\text {th }}$ harmonic, and the $7^{\text {th }}$ harmonic components (Fig. 8). The $3^{\text {rd }}$ and the multiples of $3^{\text {rd }}$ harmonic are not considered here as they are not presented in line to line components. The $5^{\text {th }}$ harmonic only and the $7^{\text {th }}$ harmonic only are of low frequency. The $5^{\text {th }}$ harmonic and $7^{\text {th }}$ harmonic simultaneously are of high switching frequency, therefore they can be used for a low and medium load.

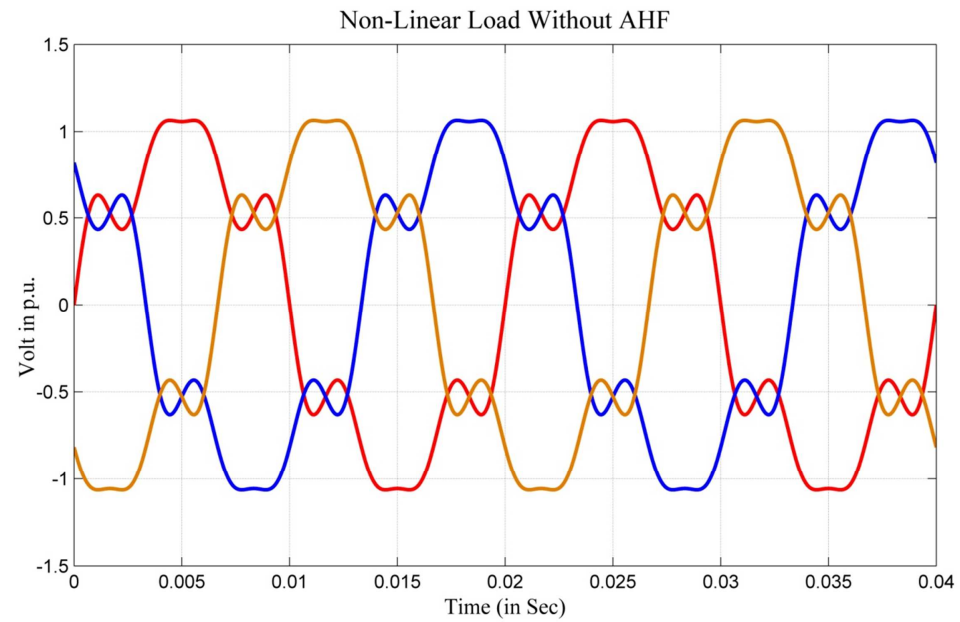

Fig. 8 The non-linear load supplied by the grid (without AHF)

\subsection{Case 2: When a non-linear load is supplied by the grid and AHF}

If the $5^{\text {th }}$ harmonic is required by the non-linear load, it is generated and supplied by AHF, and the fundamental component is supplied by the grid. In Fig. 9, the circuit is simulated, and the component of load current supplied by the grid and AHF is shown.

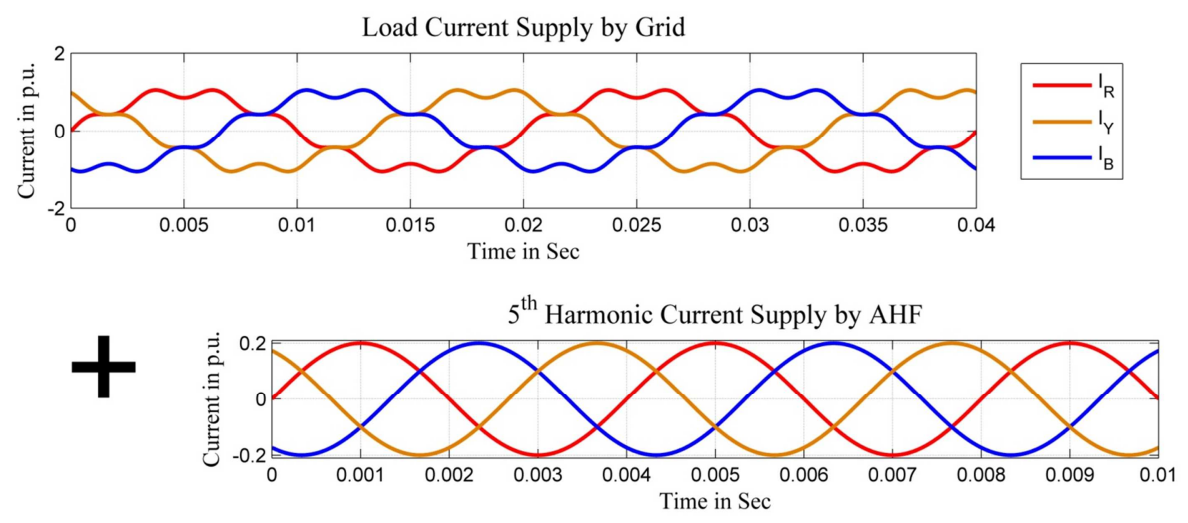

Fig. 9 The fundamental and the $5^{\text {th }}$ harmonic component of load current supplied by AHF and grid

Similarly, the $7^{\text {th }}$ harmonic and fundamental component required by the load is shown in Fig. 10. However, in this case, the grid quality is not very good because the harmonics are also presented in the grid. Therefore, these harmonics must be removed. 


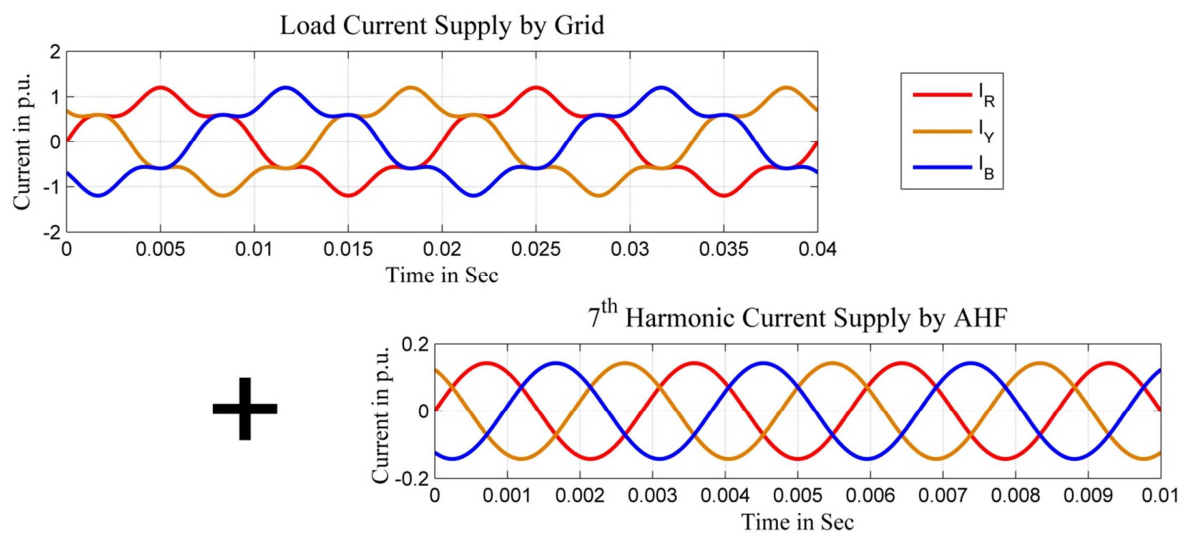

Fig. 10 The fundamental and the $7^{\text {th }}$ harmonic component of load current supplied by AHF and grid

If the non-linear load consists of both of the $5^{\text {th }}$ and 7 th harmonics, then both of the $5^{\text {th }}$ and $7^{\text {th }}$ harmonic components of load current are supplied by AHF, as shown in Fig. 11. Also, the load current is supplied by the grid which is sinusoidal in nature and the overall grid quality is improved, as shown in Fig. 11.

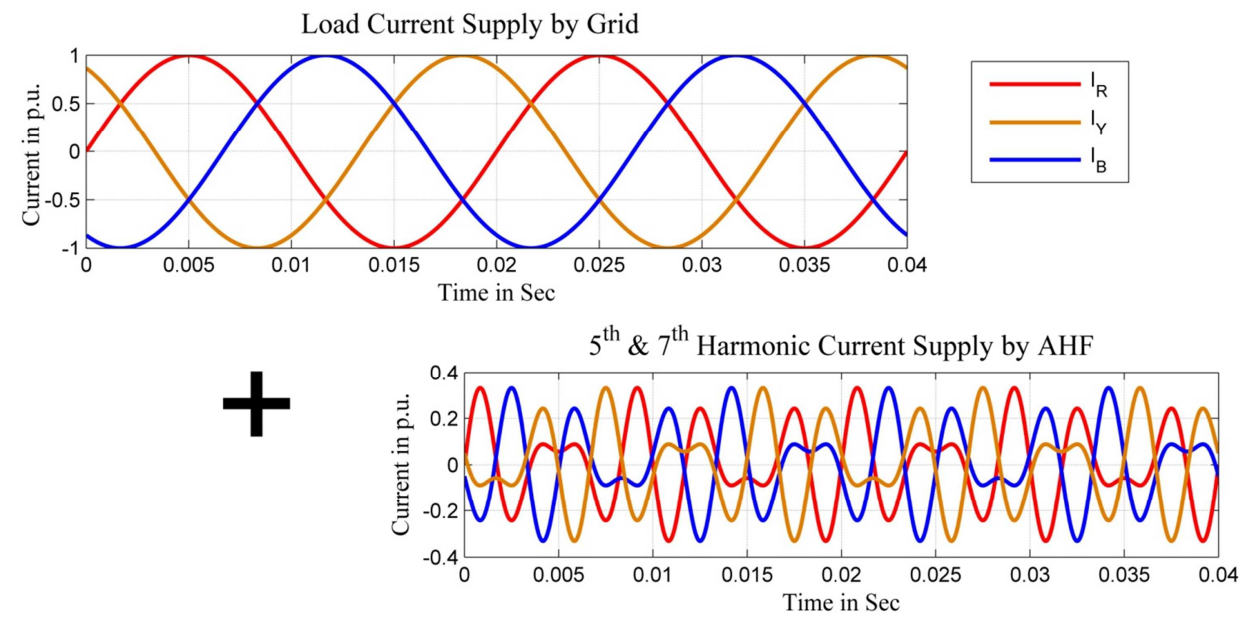

Fig. 11 The load current supplied by grid and the $5^{\text {th }}$ and $7^{\text {th }}$ harmonic components of load current supplied by AHF

It is clear from the above-mentioned results that the load current supplied by grid is nearly sinusoidal. The conditions with and without AHF harmonic component of $100 \mathrm{~kW}$ at UPF load are compared and shown in Fig. 12.

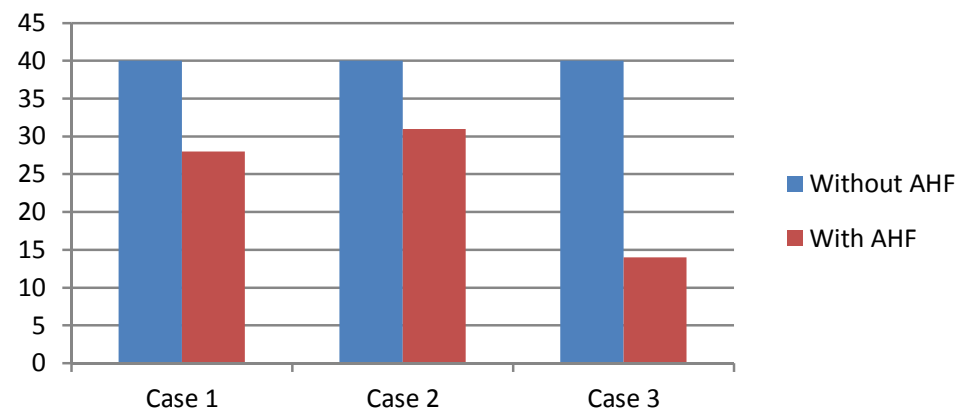

Fig. 12 The harmonic comparison with and without AHF

In this studied case, the droop controller works in the grid-connected mode as well as in the islanded mode. In the grid-connected mode, the droop controller works as AHF and reduces THD. It has not given desired results by eliminating only the $5^{\text {th }}$ or only the $7^{\text {th }}$ harmonic by taking three $\alpha_{1}, \alpha_{2}, \alpha_{3}$ switching instances, but it has given desired results by taking the $5^{\text {th }}$ and $7^{\text {th }}$ harmonic elimination simultaneously. We use only a simple pulse generator for this task, and for reducing THD further, we can use more switching instances such as $\alpha_{1}, \alpha_{2}, \alpha_{3}$, and so on. It requires a high computation technique, which is possible in the present time. 


\subsection{Case 3: When the non-linear load is supplied by distributed generator}

If the grid is disconnected, the electrical power is supplied by the distributed generator [19]. Now, the operation of the droop controller shifts from AHF to the conventional droop controller with Advanced Filtering Technique (AFT).

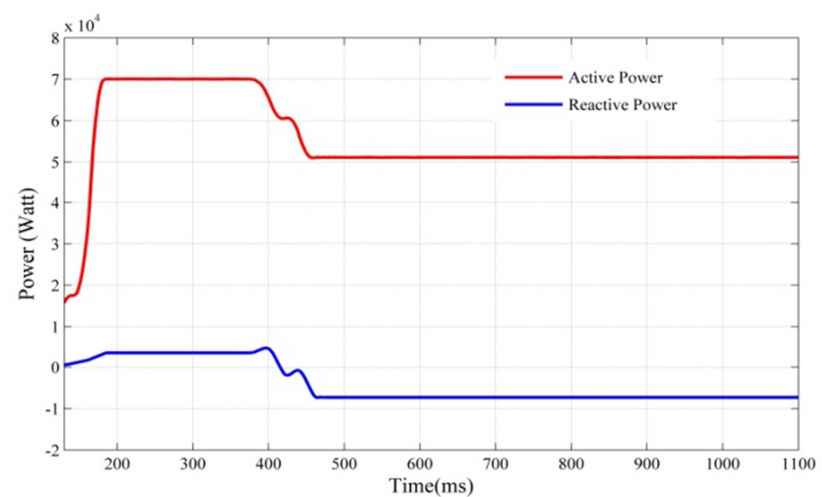

(a) Power delivered by D1 (without AFT)

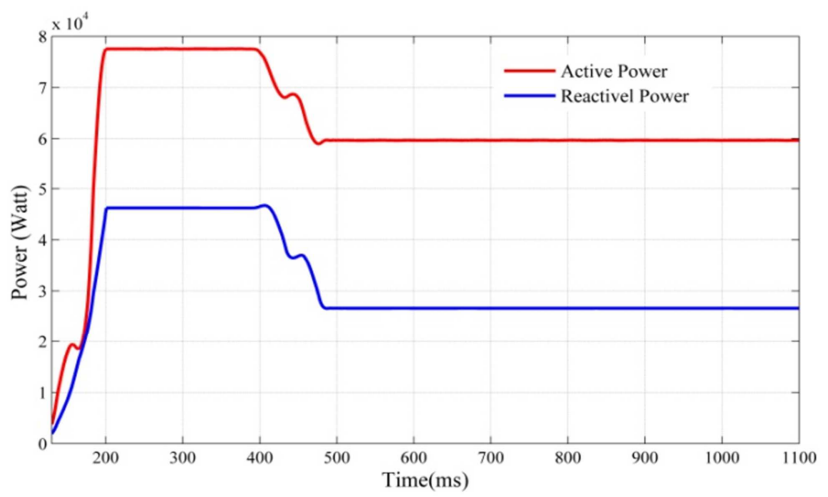

(c) Power delivered by D1 (with AFT)

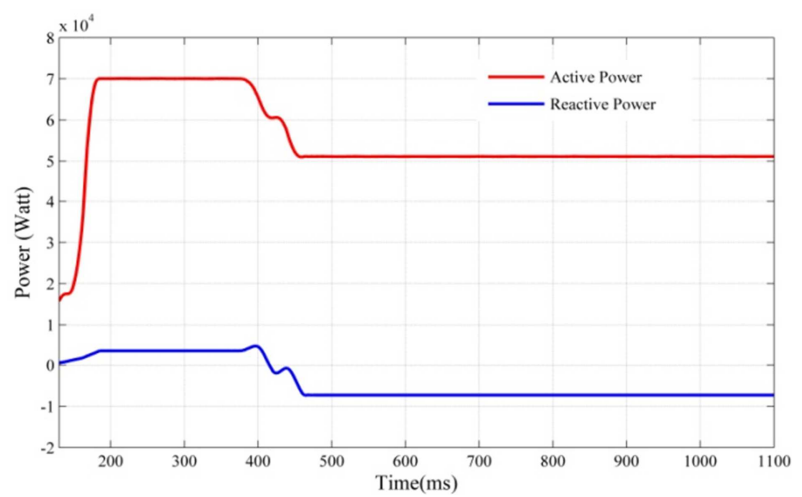

(b) Power delivered by D2 (without AFT)

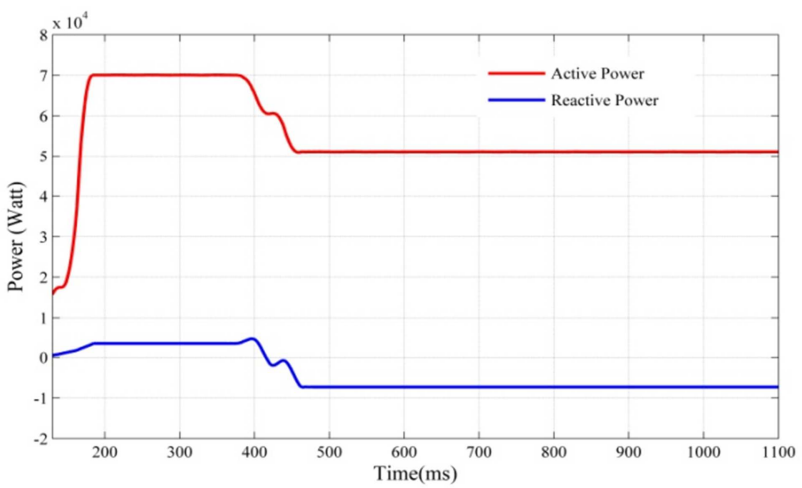

(d) Power delivered by D2 (with AFT)

Fig. 13 The active and reactive power sharing by both DG systems

It starts the following droop characteristics. Here in Fig. 13, the electrical power-sharing of two DG systems is shown. The active and reactive power sharing by both DG systems is according to Fig. 13. This figure shows the variation of active and reactive power in the DG system. It is evident that in the islanded mode this controller works in a normal way so that power can provide according to the load requirements. As per Fig. 13, the droop controller supplies the active and reactive power to the load (described in Fig. 13(a) and Fig. 13(c)) without AFT. Fig. 13(b) and Fig. 13(d) represent the active and reactive powers supplied to load with AFT. The only difference is that the reactive power supplied with AFT is more. Therefore, we can say that the reactive power is required with AFT. The requirement of reactive power is lesser when AFT is embedded with conventional droop controller.

\section{Conclusions}

This paper has presented an improvised droop controller strategy for controlling power in the grid-connected and in the islanding mode. A detailed description of the operation of the droop controller is given in the grid-connected and in the lock-down mode. In the grid-connected mode, a new technique SHG is used so that the droop controller can supply the desired harmonic component to a non-linear load, and the overall THD can be reduced. In the lock-down mode, the conventional droop characteristics with advanced filtering features reduce the requirement of reactive power. Especially, this controller provides a complete solution in all conditions with a slight modification in pulse generation techniques with advanced filter designing.

\section{Conflicts of Interest}

The authors declare no conflict of interest. 


\section{References}

[1] D. Carmon, A. Navon, R. Machlev, J. Belikov, and Y. Levron, "Readiness of Small Energy Markets and Electric Power Grids to Global Health Crises: Lessons From the COVID-19 Pandemic,” IEEE Access, vol. 8, pp. 127234-127243, 2020.

[2] A. A. Alkahtani, S. T. Alfalahi, A. A. Athamneh, A. Q. Al-Shetwi, M. B. Mansor, M. A. Hannan, et al., "Power Quality in Microgrids Including Supraharmonics: Issues, Standards, and Mitigations,” IEEE Access, vol. 8, pp. 127104-127122, 2020.

[3] A. Molderink, V. Bakker, M. G. Bosman, J. L. Hurink, and G. J. Smit, "Management and Control of Domestic Smart Grid Technology," IEEE Transactions on Smart Grid, vol. 1, no. 2, pp. 109-119, September 2010.

[4] A. E. M. Bouzid, P. Sicard, H. Chaoui, A. Cheriti, M. Sechilariu, and J. M. Guerrero, "A Novel Decoupled Trigonometric Saturated Droop Controller for Power Sharing in Islanded Low-Voltage Microgrids,” Electric Power Systems Research, vol. 168, pp. 146-161, March 2019.

[5] Y. Zhang, N. Gatsis, and G. B. Giannakis, "Robust Energy Management for Microgrids with High-Penetration Renewables," IEEE Transactions on Sustainable Energy, vol. 4, no. 4, pp. 944-953, October 2013.

[6] Y. Han, X. Ning, P. Yang, and L. Xu, "Review of Power Sharing, Voltage Restoration and Stabilization Techniques in Hierarchical Controlled DC Microgrids," IEEE Access, vol. 7, pp. 149202-149223, 2019.

[7] R. Haider, C. H. Kim, T. Ghanbari, S. B. A. Bukhari, M. S. uz Zaman, S. Baloch, et al., "Passive Islanding Detection Scheme Based on Autocorrelation Function of Modal Current Envelope for Photovoltaic Units," IET Generation, Transmission \& Distribution, vol. 12, no. 3, pp. 726-736, February 2018.

[8] A. Rostami, M. Bagheri, S. B. Naderi, M. Negnevitsky, A. Jalilian, and F. Blaabjerg, “A Novel Islanding Detection Scheme for Synchronous Distributed Generation Using Rate of Change of Exciter Voltage Over Reactive Power at DG-Side," Australasian Universities Power Engineering Conference, November 2017, pp. 1-5.

[9] A. Llaria, O. Curea, J. Jimenez, and H. Camblong, "Survey on Microgrids: Analysis of Technical Limitations to Carry Out New Solutions," 13th European Conference on Power Electronics and Applications, September 2009, pp. 1-8.

[10] H. Han, X. Hou, J. Yang, J. Wu, M. Su, and J. M. Guerrero, "Review of Power Sharing Control Strategies for Islanding Operation of AC Microgrids,” IEEE Transactions on Smart Grid, vol. 7, no. 1, pp. 200-215, January 2016.

[11] A. M. Bouzid, M. A. Hamida, M. R. Kafi, and H. Chaoui, "Robust Angle Droop Controller Based on Pilot Point Voltage Measurement in Low-Voltage Microgrid," 1st International Conference on Sustainable Renewable Energy Systems and Applications, IEEE Press, December 2019, pp. 1-6.

[12] Y. Wang, H. Jiang, L. Zhou, and P. Xing, “An Improved Adaptive Droop Control Strategy for Power Sharing in Micro-Grid,” 8th International Conference on Intelligent Human-Machine Systems and Cybernetics, August 2016, pp. 50-53.

[13] H. Bierk, A. Albakkar, and E. Nowicki, "Harmonic Reduction in the Parallel Arrangements of Grid-Connected Voltage Source Inverters," 2nd International Conference on Electric Power and Energy Conversion Systems, IEEE Press, November 2011, pp. 1-6.

[14] A. Reznik, M. G. Simões, A. Al-Durra, and S. M. Muyeen, "LCL Filter Design and Performance Analysis for Grid-Interconnected Systems,” IEEE Transactions on Industry Applications, vol. 50, no. 2, pp. 1225-1232, March-April 2014.

[15] A. M. Bouzid, P. Sicard, J. Paquin, and A. Yamane, “A Robust Control Strategy for Parallel-Connected Distributed Generation Using Real-Ttime Simulation,” IEEE 7th International Symposium on Power Electronics for Distributed Generation Systems (PEDG), IEEE Press, June 2016, pp. 1-8.

[16] S. Jayalath and M. Hanif, “Generalized LCL-Filter Design Algorithm for Grid-Connected Voltage-Source Inverter,” IEEE Transactions on Industrial Electronics, vol. 64, no. 3, pp. 1905-1915, March 2017.

[17] S. Behera, S. K. Behera, and B. B. Pati, "Impact of DFIG in Wind Energy Conversion System for Grid Disturbances," Proceedings of Engineering and Technology Innovation, vol. 13, pp. 10-19, July 2019.

[18] R. D. Patidar and S. P. Singh, "Harmonics Estimation and Modeling of Residential and Commercial Loads," International Conference on Power Systems, IEEE Press, December 2009, pp. 1-6.

[19] R. Majumder, A. Ghosh, G. Ledwich, and F. Zare, “Angle Droop Versus Frequency Droop in a Voltage Source Converter Based Autonomous Microgrid,” IEEE Power \& Energy Society General Meeting, July 2009, pp. 1-8. 